\title{
Learn from Leaders \#4: Building a Team
}

\section{Daniel Forbes (University of Minnesota, Carlson School of Management) Jon Eckhardt (University of Wisconsin-Madison)}

KEYWORDS: Leadership, Startups, human resources.

This is the fourth video in our exclusive series called "Learn from Leaders," featuring advice for early-stage entrepreneurs and innovators from founders and CEOs of groundbreaking companies. Each of our Learn from Leaders videos focuses on an important step in launching a company. This one focuses on how to attract and incentivize your startup team, and how those teams can evolve as the company matures.

Our interview subjects include Best Buy founder and retired CEO Dick Schulze; Scott Nash, founder of Mom's Organic Market; Seth Goldman, founder of Honest Tea; and Eddie Hartman, founder of LegalZoom.

\section{Video Produced by John Buday} LEARN MORE

\section{Explore our "Learn From Leaders" Series}

(https://eiexchange.com/content/learn-from-leaders-

famous-founders-best-advice-for-new-ventures)

\section{LISTEN}

Listen to our original interviews with each of these leaders and others on our podcast channel on Soundcloud.

Link to video

\section{EIX}

(https://soundcloud.com/user-876519212-189256831).

Learn From Leaders: Conversations with Famous Entrepreneurs

(https://soundcloud.com/user-876519212-189256831/s ets/learn-from-leaders) 